'|||||||||||||||||||||||||||||||||||||||||||||||||||||||||||||||||||.

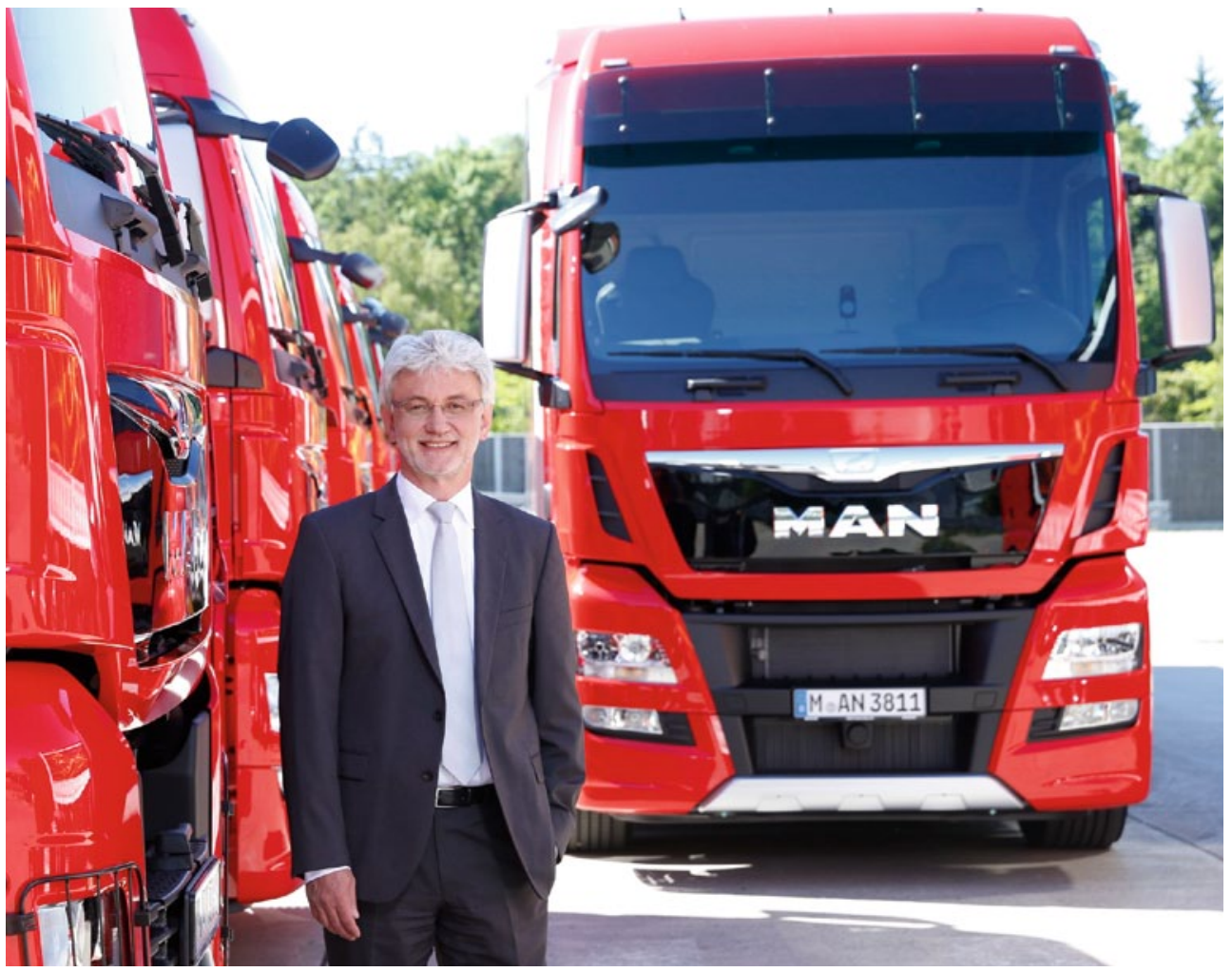

DIPL.-ING. BERND MAIERHOFER

Vorstand für Forschung \& Entwicklung (F\&E), MAN Truck \& Bus AG

\title{
EFFIZIENZ TRIFFT PERFORMANCE
}

Die bevorstehende IAA markiert den Abschluss der Markteinführung der Euro-VI-Fahrzeuge, die von einem Komplexitätsschub vor allem durch die Abgasnachbehandlung geprägt sind. In diesen Tagen stellt MAN die D38-Fahrzeuge mit dem neuen 15,2-1-Motor D3876 vor. Mit diesem Motor komplettiert MAN das Euro-VI-Motorenprogramm mit den Leistungsstufen 382, 412 und 471 kW. Der neue D38-Motor ist als Sechszylindermotor konsequent auf dieses Leistungssegment ausgerichtet und bedient die Anforderungen sowohl des anspruchsvollen, verbrauchssensiblen Fernverkehrs als auch der Baustelle und des Schwertransports.

Der Sechszylinder löst den V8-Motor in MAN-Fahrzeuganwendungen ab und ermöglicht durch sein geringes Eigengewicht hohe Nutzlasten und geringere Kraftstoffverbräuche. Hohe Zünddruckfähigkeit und zweistufige Abgasturboaufladung in Verbindung mit einem modernen 2500-bar-Einspritzsystem sowie zweistufig gekühlte Abgasrückführung sind wesentliche Konzeptbausteine, um einen hohen thermodynamischen Wirkungsgrad zu erreichen. Sein Aufladungskonzept sorgt für ein besonders breites Drehmomentplateau schon ab 930/min, was in Verbindung mit einem anwendungsspezifisch angepassten Triebstrang verbrauchsgünstige niedrige Motordrehzahlen gewährleistet.
Mit dem weiterentwickelten Schaltsystem MAN TipMatic II, den neuen Getriebefunktionen (Speedshifting, Efficient Roll, Idle Speed Driving) sowie dem GPS-gestützten Tempomat EfficientCruise stellt MAN den Speditionen und Lkw-Fahrern technische Lösungen zur Verfügung, die sich in der Praxis durch hohe Wirtschaftlichkeit insbesondere in schweren Einsätzen auszeichnen. Im Rahmen einer vom Fahrer gewählten Wunschgeschwindigkeit sowie einer ebenfalls vom Fahrer beeinflussbaren Geschwindigkeitstoleranz passt der GPS-Tempomat die Fahrgeschwindigkeit unter Einbeziehung der Topografie kraftstoffverbrauchsoptimiert an. Mit ihm wird der Trend zum automatisierten Fahren beim Nutzfahrzeug schon heute aufgegriffen. Dies gewinnt auch bei den Spediteuren zunehmend an Bedeutung. Denn hohe Effizienz, Zuverlässigkeit und Wirtschaftlichkeit sind die Schlüsselfaktoren zum Erfolg bei unseren Kunden.

Wir fokussieren unsere Entwicklungstätigkeiten auf die Verbesserung von Kraftstoffverbrauch und $\mathrm{CO}_{2}$-Effizienz. Neben der Weiterentwicklung unserer Diesel- und Gasantriebe setzt MAN bewusst auch auf Hybridisierung. Die Synergien mit den Volkswagen-Konzernpartnern erlauben es uns, in diesem preissensiblen Kundenumfeld wettbewerbsfähige Produkte zu entwickeln. 